Cases of infection with penicillinase producing Neisseria gonorrhoeae (PPNG) reported to Communicable Disease Surveillance Centre (CDSC) and St Thomas's Hospital

\begin{tabular}{|c|c|c|c|c|c|}
\hline Year & $\begin{array}{l}\text { Cases reported } \\
\text { to CDSC }\end{array}$ & $\begin{array}{c}\text { Cases of PPNG infection } \\
\text { at St Thomas's }\end{array}$ & $\begin{array}{l}\text { PPNG infection at St Thomas's } \\
\text { as \% of reports to CDSC }\end{array}$ & $\begin{array}{l}\text { Cases of gonorrhoea } \\
\text { at St Thomas's }\end{array}$ & $\begin{array}{l}\text { PPNG infection as \% of cases } \\
\text { of gonorrhoea at St Thomas's }\end{array}$ \\
\hline 1986 & 699 & 86 & $12 \cdot 3$ & 1413 & $6 \cdot 1$ \\
\hline 1987 & 379 & 32 & $8 \cdot 4$ & 867 & $3 \cdot 7$ \\
\hline 1988 & 289 & 25 & 8.7 & 588 & $4 \cdot 3$ \\
\hline 1989 & 246 & 59 & $24 \cdot 0$ & 907 & 6.5 \\
\hline 1990 & 269 & 54 & $20 \cdot 1$ & 1019 & $5 \cdot 3$ \\
\hline 1991 & 192 & 54 & $28 \cdot 1$ & 1026 & $5 \cdot 3$ \\
\hline
\end{tabular}

endemic in London, ${ }^{2}$ later analysis has proved this wrong (table) despite this organism's success elsewhere in the world.

Though under half of infections presenting to the genitourinary medicine clinic at this hospital have been acquired outside the United Kingdom, $90 \%$ of our patients infected with penicillinase producing Neisseria gonorrhoeae have a demonstrable foreign connection and "second generation" sexual transmission is rare. Far from thriving, penicillinase producing Neisseria gonorrhoeae seems to need constant topping up.

Heterosexual syphilis remains uncommon in the United Kingdom. After a clutch of cases in the late $1980 \mathrm{~s}^{3}$ we saw 22 cases of early infectious syphilis in heterosexuals during 1989-91, of which 14 were imported. Our figures are borne out nationally: a review of sexually transmitted diseases from the Communicable Disease Surveillance Centre stated that an increasing proportion of cases of infection with penicillinase producing Neisseria gonorrhoeae and syphilis were acquired abroad during 1981-90 while the overall numbers continued to decline. ${ }^{4}$ If both of these infections are examples of the likely future of HIV infection in heterosexuals in the United Kingdom there may be hope as neither has established itself in the heterosexual community.

Finally, is it a little disingenuous to write (correctly) that the Cox and Day reports "emphasised the great uncertainty concerning future heterosexual spread" when the Department of Health and others have tended to quote the more pessimistic predictions (of exponential spread) rather than quoting that "a lower scenario, also consistent with available data, is that little new transmission is taking place... and that only minor increases will be seen in the next few years in the yearly number of cases due to injecting drug use or heterosexual contact."

DAVID BARLOW

J SHERRARD

St Thomas's Hospital,

London SE1 7EH

1 Johnson AM. Home grown heterosexually acquired HIV infection. BMF 1992;304:1125-6. (2 May.)

2 Thin RN, Barlow D, Eykin S, Phillips I. Imported penicillinase producing Neisseria gonorrhoeae becomes endemic in producing Neisseria gonorrhoeae

3 Tang A, Barlow D. Resurgence of heterosexually acquired early syphilis in London. Lancet 1989;ii: 166-7.

4 Catchpole MA. Sexually transmitted diseases in England and Wales: 1981-1990. Communicable Disease Report 1992;Jan: R1-7.

5 Ades AE, Parker S, Berry T, Holland FJ, Davison CF, Cubitt D, et al. Prevalence of maternal HIV-1 infection in Thames regions: results from anonymous unlinked neonatal testing. Lancet 1991;337:1562-6.

6 Day NE, Anderson RM, Daykin CD, et al. Acquired immune deficiency syndrome in England and Wales to end 1993. Projections using data to end September 1989. Communicable Disease Report 1990; Jan:1-12.

AUTHOR'S REPLY, - David Barlow and J Sherrard comment on the current incidence of penicillinase producing Neisseria gonorrhoeae and syphilis in heterosexuals in the United Kingdom. My comments on the importation of sexually transmitted diseases were, however, clearly made in a historical context. Syphilis indeed thrived in heterosexuals in the United Kingdom and throughout Europe for nearly 500 years, resulting in a heavy toll in morbidity and mortality. Though accurate figures are hard to come by before formal notification began, surveys in 1914 suggested that
$12 \%$ of men and $7 \%$ of women in London suffered from acquired syphilis.' In 1925 reported cases of newly diagnosed syphilis in men and women exceeded 23000 a year. ${ }^{2}$ As Barlow and Sherrard indicate, infection with penicillinase producing Neisseria gonorrhoeae showed every sign of establishing itself as endemic in the early 1980s. In 1982 more than $70 \%$ of cases were acquired in the United Kingdom. ${ }^{3}$ Where infection with penicillinase producing Neisseria gonorrhoeae and syphilis part company from HIV infection is in the current availability of a highly effective cure. Rates of syphilis declined rapidly after the introduction of penicillin in the 1940s. Awareness of a rising incidence of infection with penicillinase producing Neisseria gonorrhoeae resulted in control measures, which included wider use of alternative antibiotics to penicillin and contact tracing through a comprehensive sexually transmitted disease service in the United Kingdom.

No effective cure yet exists for infection with HIV, the spread of which remains determined by its biological properties and by sexual and drug injecting behaviour patterns. Comparisons between the future prevalence of HIV and the current incidence of infection with penicillinase producing Neisseria gonorrhoeae and of syphilis are therefore unhelpful. In discussing the importation of sexually transmitted disease I had hoped to help readers take a longer term view of the problem and to consider the lessons of history.

Finally, Barlow and Sherrard reiterate the point that I made in my editorial that the Cox and Day reports emphasise uncertainty and present various projections consistent with the available data over the relatively short period of four years. In an attempt to put a balanced scientific view of heterosexually acquired HIV infection I deliberately referred to the official predictions of future spread and not to any secondary sources which have chosen to present selectively the extremes of the range of feasible scenarios discussed in these reports.

ANNE M JOHNSON

Academic Department of Genitourinary Medicine,

University College and Middlesex School of Medicine,

London WIN 8 AA

1 Adler MW. The terrible peril: a historical perspective on the nereal diseases. BMF 1980;281:206-11.

2 Academic Department of Genitourinary Medicine of Middlesex Hospital Medical School, Communicable Surveillance Centre, Communicable Diseases (Scotland) Unit. Sexually transmitred disease surveillance, 1978. BM7 1979;ii:1375-6.

3 Public Health Laboratory Service Communicable Disease Surveillance Centre, Communicable Diseases (Scotland) Unit, Academic Department of Genitourinary Medicine of Middlesex Hospital Medical School. Penicillinase-producing Neisseria gonorrhoeae in Britain 1982. BMJ 1983;286:1628-9.

\section{Treatment of allergy}

EDITOR, - The title of a recent news item by Luisa Dillner- "Alternative allergy treatments need clinical trials"- was slightly misleading since the second paragraph of the article was concerned with Professor Stephen Holgate's statements on the competence of certain doctors to treat allergy. ${ }^{1} \mathrm{He}$ is reported as saying, "We haven't recognised the importance of training people to treat allergy. We base our referral systems on organs and not on disease processes. . . Ophthalmologists and ENT surgeons see a lot of people with problems due to allergy but have no training in treating it." We believe that these comments are critical of the present systems of referral, as well as postgraduate training, and take issue with them.

Presentation is symptom based, and the subsequent assessment should result in diagnosis. Although patients may make an attempt at diagnosis, they rarely enter the clinic saying, for example, "I have a type one hypersensitivity to dust mite faeces." Until this enlightened state of affairs occurs patients with nasal allergy may present with various symptoms identical with those of other nasal and sinus conditions. The specialist has to be able to exclude not only the common conditions but also the rare ones that may cause symptoms. Part of this process entails examining the nose-few people outside the specialty of otolaryngology can do this effectively.

Though no courses are devoted exclusively to allergy, its importance is well recognised in our specialty. One of us has organised courses in practical rhinology which started as far back as 1984, with lecturers including basic scientists, allergists, chest physicians, and otolaryngologists. Similar courses are run regularly nationwide. Candidates for the final FRCS in otolaryngology are expected to understand allergy and its treatment.

We disagree with the idea that patients take to alternative treatment solely because doctors have failed them because they do not know how to treat allergy. The treatment itself may be unacceptable. People turn to alternative therapy for many reasons besides the failings of doctors or their treatments. They need mystery, magic, and ritual, and nowhere is this better recognised than in the treatment of allergy by some allergists, particularly in the United States.

We, and probably many other otolaryngologists and ophthalmologists, believe that the correct and enlightened approach is the involvement of interested practitioners in the treatment of allergic diseases. The picture in Britain is not nearly as dark as that painted by Dillner.

ADRIAN DRAKE-LEF SCOTT STEVENSON

Ear, Nose, and Throat Department,

Queen Elizabeth Hospital,

Birmingham B15 2TH

Dillner L. Alternative allergy treatments need clinical trials.

BMF 1992;304: 1003. (18 April.)

\section{Cardiac arrest associated with flumazenil}

EDIToR,--In their drug point Yeshayahu Katz and colleagues report on a 60 year old man admitted with an extensive acute anterior wall myocardia infarction. ' Adverse prognostic features included cardiac failure complicated by pulmonary oedema (serious enough to require mechanical ventilation) and haemodynamic instability associated with ventricular arrhythmia. The patient began to resist ventilation but was still drowsy, an effect considered to be secondary to the sedative action of diazepam. Details of the patient's cardiopulmonary status at this time are not provided. To facilitate weaning from the ventilator a total of $0.4 \mathrm{mg}$ of the specific benzodiazepine antagonist flumazenil was given intravenously. This was followed by a refractory ventricular arrhythmia, asystole, and death

The authors conclude that the fatal arrhythmia was due to a direct effect of flumazenil. They point out that this mode of action differs from that reported in earlier cases of death after flumazenil, in which the fatal event was a wearing off of antagonist activity. ${ }^{2}$

Kat $z$ and colleagues' statements and conclusions are misleading. In their quoted references the 
death reported by $\mathrm{Lim}^{2}$ is unlikely to have been due to flumazenil, ${ }^{+}$while the mechanism of action in the death reported by Burr et al was a withdrawal of the protective action of benzodiazepines in a patient who had taken a multiple drug overdose. ${ }^{3}$ The same mechanism also explains the precipitation of ventricular arrhythmias in the report that Katz and colleagues quote in support of their own case. $^{5}$

Benzodiazepines have a dampening effect on sympathetic nervous system activity, ${ }^{6}$ and animal studies suggest that they can increase the electrical stability of the heart in patients with acute myocardial infarction. ${ }^{7}$ There is little doubt that sympathetic activity in restless, waking, intubated patients is increased. This is primarily the result of irritation due to the endotracheal tube, a response that is augmented in the presence of hypoxia or pain, or both. In this setting reversing sedation with flumazenil unmasks increased sympathetic drive and cardiac electrical instability, thereby precipitating ventricular arrhythmias in an already severely damaged myocardium with compromised left ventricular function.

The conclusion can be only that the fatal drug actions in this case are similar to those reported elsewhere. ${ }^{35}$ There is no evidence for any direct cardiac effect of flumazenil.

BRIAN R P BIRCH

Department of Urolog

Southampton University Hospitals,

Southampton SO9 $4 \mathrm{XY}$

1 Katz Y, Boulos M, Singer P, Rosenberg B. Cardiac arrest associated with flumazenil. $B M F$ 1992;304:1415. (30 May.)

2 Lim AG. Death after flumazenil. BMF 1989;299:858-9.

3 Burr W, Sandham P, Judd A. Death after flumazenil. BMF 1989;298:1713.

4 Birch BRP, Miller R. Death after flumazenil? BMf 1990;300: 467-8.

5 Short TG, Maling T, Galletly DC. Ventricular arrhythmia precipitated by flumazenil. BMF 1988;296:1070-1

6 Marty J, Gauzit R, Lefevre P, Couderc E, Farinotti R, Henzel C et al. Effects of diefere et al. Effects of diazepam and midazolam on baroreflex control
of heart rate and on sympathetic activity in humans. Anesth
Analg 1986;65:113-9.

7 Hess L, Vrana M, Vranova Z, Fejfar Z. A comparison of the antifibrillatory effect of midazolam and flunitrazepam in antifibrillatory effect of midazolam and flunitrazepam in
acute myocardial ischaemia in the dog. Curr Med Res Opin
1987;10:527-30.

\section{Preschool screening for cryptorchidism}

EDITOR, - In describing the epidemiology of testicular cancer G M Mead relates $10 \%$ of testicular cancers to histories of unilateral or bilateral testicular maldescent. ${ }^{1}$ In addition to cancer, testicular maldescent carries risks of infertility, torsion, and psychological effects. This highlights the need for effective screening programmes among preschool children to detect cryptorchidism and to provide appropriate treatment before 6 years of age. ${ }^{2}$

A quick analysis of hospital activity data in Wales for the six years 1985-90 (table) shows that in 1990 only $39 \%$ of all children were operated on before the recommended age of 6 (range 24.5$54 \cdot 4 \%$ in 1985 and $26 \cdot 2-46 \cdot 5 \%$ in 1990 ). Although the numbers operated on before the age of 6 increased slightly during the period studied, the progress was deplorably slow-just $7 \cdot 6 \%$ in six years.

In Wales local strategies for health gain are being

Age of children at orchidopexy in Wales, 1985-90. Figures are numbers (percentages) of children

\begin{tabular}{cccc}
\hline & \multicolumn{3}{c}{ Age at orchidopexy (years) } \\
\cline { 2 - 4 } Year & $<6$ & $6-10$ & $10-14$ \\
\hline 1985 & $151(31 \cdot 5)$ & 228 & 101 \\
1986 & $230(34 \cdot 2)$ & 337 & 106 \\
1987 & $206(33 \cdot 7)$ & 304 & 101 \\
1988 & $176(35 \cdot 2)$ & 238 & 86 \\
1989 & $197(36 \cdot 7)$ & 238 & 102 \\
1990 & $173(39 \cdot 1)$ & 184 & 85 \\
\hline
\end{tabular}

developed in 10 areas. $^{3}$ Minimum datasets are provided to the directors of public health medicine from the Health Intelligence Unit (a central data collection and information unit for Wales) with the intention that the districts will use this information in developing local strategies and prioritising issues of greater need. Data on the treatment of undescended testis have been provided for the first time to all districts in the hope that their regular review will provide treatment to those children requiring orchidopexy within the first six years of life. Surely orchidopexy is far easier and simpler than the treatment of testicular cancer, infertility, or emotional problems associated with this condition. Community paediatricians and paediatric surgeons, along with public health physicians, have an important role in preventing complications of this condition later in life.

SURINDER A KAUL

Health Intelligence Unit,

Welsh Health Common Services Authority,

Cardiff CF2 1SB

D P W ROBERTS

Gwynedd Health Authority,

Bangor,

Gwynedd LL57 4TP

1 Mead GM. Testicular cancers and related neoplasms. BMF 1992;304:1426-9. (30 May.)

2 Chilvers C, Dudley NE, Gough MH, Jackson MB, Pike MC. Undescended testis: the effect of treatment on subsequent risk of subfertility and malignancy. F Pediatr Surg 1986;21:691-6.

3 Welsh Health Planning Forum. Strategic intent and direction for NHS in Wales. Cardiff: Welsh Office, 1989.

\section{Lung cancer and radon}

EDITOR, - Stephen J Wozniak doubts the economic benefit of lowering radon levels in buildings on a mass scale to reduce the incidence of lung cancer. ${ }^{\prime}$ $\mathrm{He}$ is right to say this, particularly as there is as yet no proof that radon in dwellings causes lung cancer. ${ }^{23}$

Cornwall has been designated a high risk area by the National Radiological Protection Board, and many people are having their properties tested. When a high level is found (over $200 \mathrm{~Bq} / \mathrm{m}^{3}$ ) householders are tempted to install ventilation systems to reduce the level. The standardised mortality ratio for lung cancer in the county for $1986-90$, however, is 79 , which scarcely suggests that radon is having a major effect.

An important study by the Imperial Cancer Research Fund is under way in Cornwall to test the hypothesis linking radon with lung cancer. ${ }^{4}$ Until this has reported, my advice to any inquirers is to delay a decision on remedial action in any domestic property

D P B MILES

Cornwall and Isles of Scilly Health Authority, Truro TR1 INR

Wozniak SJ. Lung cancer and radon. BMf 1992;304:1571 (13 June.)

2 Bowie C, Bowie SHU. Radon and health. Lancet 1991;337 409-13.

Abelson PH. Mineral dusts and radon in uranium mines. Science 1991;254:777.

4 Darby SC, Doll R, Sayers K, Silcocks P, Thakrar B. Study of indoor air pollution and health: progress report October 1991. London: Imperial Cancer Research Fund Cancer Epidemiology Unit, 1991.

\section{Symptoms after accelerated immunisation}

EDIToR,-Mary E B Ramsay and colleagues conclude that local and systemic reactions occurred less commonly after accelerated immunisation schedules than after the standard schedule. ${ }^{1}$ They found that redness and swelling at the injection site were significantly reduced in those children who received the accelerated schedule. The two groups, however, were immunised at different sites: $89 \%$ of the control group were immunised in the thigh, and $89 \%$ of those given the accelerated schedule were immunised in the buttock.

In their discussion the authors argue that both a British study and an American study failed to show any difference in symptoms after immunisation at different sites. ${ }^{23}$ The results of these studies, however, are by no means conclusive: the British study compared types of vaccination rather than vaccination site, and the American study failed to control vaccine dose. Moreover, Ipp et al concluded that immunisations at different sites did have a significant bearing on the severity of local reactions, reactions in the thigh being more severe than those in the upper arm. ${ }^{4}$ We therefore believe that the site of immunisation may be a confounding variable when the results of this study are being interpreted.

DAVID BURGNER PHILIP CHETCUTI

Southmead Hospital,

Bristol BS10 5NB

1 Ramsay MEB, Rao M, Begg NT. Symptoms after accelerated immunisation. BMF 1992;304:1534-6. (13 June.)

2 Pollock TM, Miller E, Mortimer JY, Smith G. Symptoms afte primary immunisations with DTP and DT vaccine. Lancet 1984;ii: 146-9.

3 Barraff LJ, Cody CL, Cherry JD. DPT-associated reactions: an analysis by injection site, manufacturer, prior reactions, and dose. Pediatrics 1984;73:31-6.

4 Ipp MM, Gold R, Goldbach M, Maresky DC, Saunders N, Greenburg S, et al. Adverse reactions to diphtheria, tetanus, pertussis-polio vaccination at 18 months of age: effect of injection site and needle length. Pediatrics 1989;83:679-82.

\section{Monitoring ambulatory blood pressure in general practice}

EDITOR,-We believe that some of David J Webb and colleagues' concerns about the widespread introduction of monitoring of ambulatory blood pressure in general practice are valid but that their conclusion, that the introduction of the technique in general practice should be postponed pending the outcome of clinical trials, is misguided.

That ambulatory blood pressure is superior in refining risk is not in dispute. The problem is that the criteria for treatment based on ambulatory readings are not well defined, and this is especially difficult in the care of patients with high clinic readings and low ambulatory readings. If ambulatory blood pressure is to be used for making decisions about hypertensive patients in the future then it is essential for research to include subjects in general practice.

In Oxfordshire the family health services authority has recently made ambulatory blood pressure units available to 50 general practices. Training in their use and appropriate support are being provided. Various collaborative research projects involving these general practices are being planned by the department of cardiovascular medicine and the department of public health and primary care in Oxford University.

In the meantime any implication that general practitioners will make wholesale changes to the treatment of hypertensive subjects by denying treatment to those with raised clinic pressure but normal ambulatory pressures (using similar criteria for intervention) is unfair. General practitioners are capable of interpreting the evidence as well as heeding the advice of specialist physicians. We believe that there is a strong place for moving monitoring of ambulatory blood pressure selectively into general practice provided its curren limitations are emphasised, appropriate training and support are offered, and the monitoring units meet acceptable technical and performance standards.

Rather than agreeing with Webb and colleagues' suggestion to "await the outcome of definitive clinical trials," which may never take place we would encourage greater use of ambulatory 